\title{
POST-CAESAREAN OVULATION IN THE RAT
}

\author{
N. P. JOHNSON, ${ }^{*}$ M. X. ZARROW† AND V. H. DENENBERG \\ Department of Biobehavioral Sciences, University of Connecticut, \\ Storrs, Connecticut 06268, U.S.A.
}

(Received 30th Fuly 1973)

\begin{abstract}
Summary. Delivery by Caesarean Section (CS) of pregnant rats at 09.00 hours on the 23rd day of gestation reduced the range of times of ovulation after parturition by $18 \mathrm{hr}$. Ovulation had not occurred by $15 \mathrm{hr}$ after CS but was completed by $18 \mathrm{hr}$, an interval which is similar to that of ovulation for females of this colony littering at 09.00 hours. Operation on Day 21 or 22 post coitum did not change the day of ovulation (Day 24) but CS on Days 19 or 20 advanced ovulation to Days 22 or 23, respectively. Prevention of normal delivery by ligation of the uterine horns on Day 22 resulted in no females ovulating on Day 24, and few females ovulating on Days 25 and 26. In such females, CS did not increase the number of rats ovulating.
\end{abstract}

\section{INTRODUCTION}

Female albino rats usually ovulate during the dark period following parturition (Hoffmann \& Schwartz, 1965; Johnson, 1972). The relationship of parturition to ovulation is of interest since it has been shown that the time of day of parturition has an important influence on the subsequent timing of gonadotrophin release and ovulation (Johnson, 1972).

This study was designed to determine some of the effects of parturition on subsequent ovulation. Delivery by Caesarean Section (CS) and prevention of delivery by uterine ligation were used to ascertain the effects of removal or prolonged retention of the embryos and placentae on post-partum ovulation.

\section{MATERIALS AND METHODS}

Females from our colony of Wistar-derived $W / Z$ rats were placed with males and vaginal smears were checked each morning for the presence of spermatozoa. The day on which spermatozoa were found in the smear was designated Day 1 of pregnancy, and females were then separated from the males. On Day 18 of pregnancy, the females were transferred to stainless steel maternity cages with external food and water supplies which were freely available.

\footnotetext{
* Present address: Laboratory of Endocrine Research, Department of Allied Health Education, College of Allied Health, and Department of Physiology, Howard University Medical School, Washington, D.C. 20001, U.S.A.

$\dagger$ Deceased.
} 
The lighting schedule was 13-hr light/11-hr dark with the light period starting at 07.00 hours.

A total of 163 females was checked each hour of the light period to determine the normal distribution of littering.

Delivery by CS was performed between 09.00 and 10.00 hours or between 21.00 and 22.00 hours. Each female was anaesthetized with ether, and a $2.5 \mathrm{~cm}$ longitudinal incision was made through the skin and abdominal wall midway between the genitalia and the umbilical area. The two uterine horns were pulled through the opening on to paper surgical aprons, and small incisions were made along the antimesometrial surface of each uterine horn. Fetuses were manually extruded, the abdomen was closed, and the female was restored to her cage without young. The entire surgical procedure lasted approximately $5 \mathrm{~min}$.

In an initial study, CS was performed on forty rats at 09.00 hours on Day 23. They were returned to their cages, and then groups of ten females were killed at one of the following times: 24.00 hours (15 hr after CS), 03.00 hours (18 hr), $06.00(21 \mathrm{hr})$, or 12.00 hours $(27 \mathrm{hr})$. The oviducts were removed and dissected for the recovery of eggs using the method of Zarrow, Caldwell, Hafez \& Pincus (1958). Ovulation was defined as the presence of eggs in the oviducts. If there were fewer than eight eggs, the response was designated 'partial ovulation' (Everett, 1964).

In a subsequent study, CS was performed on groups of females at 09.00 hours on Day 22, and some females were killed at various times to establish the day of ovulation for most of the animals. Other females received an injection of $40 \mathrm{mg}$ NIH-LH-S17 in $0.2 \mathrm{ml}$ physiological saline to test their ovulatory capability. Injections were given at 09.00 hours intraperitoneally or into the right saphenous vein. Additional females were delivered by CS at 21.00 hours on Days 19, 20, 21 and 22, and were killed at different times to establish the interval to complete ovulation for each day on which CS was performed.

In the concluding experiment, the uterine horns were ligated to study the effects of prolonged pregnancy on ovulation. Laparotomy was performed under ether anaesthesia on the morning of Day 22. Each uterine horn was tied just above the uterocervical junction with silk thread thick enough to prevent cutting through the tissues. The rats were killed on Day 24, 25 or 26, and the eggs were recovered and counted. Chi-square analyses of data were utilized for maximum robustness.

\section{RESULTS}

For this colony, the mean time of parturition was 10.00 hours on Day 23 post coitum, with a median at 11.00 hours and a mode at 12.00 hours. The range was from 10.00 hours on Day 22 to 12.00 hours of Day 24. During the hours of light on Day $22,11.7 \%$ of pregnant females littered, and another $3.1 \%$ gave birth during the dark period preceding the Day-23 light period.

The females which were subjected to CS at 09.00 hours on Day 23 represented approximately $65 \%$ of the total number of pregnancies, and, more importantly, the potential deliveries of the next $27 \mathrm{hr}$. 
No ovulation had occurred by $15 \mathrm{hr}$ after CS, but $100 \%$ of the females had ovulated by $18 \mathrm{hr}$ although four of the females had only 'partial ovulations'. Except for one female which had not ovulated $21 \mathrm{hr}$ after CS (06.00 hours), all females killed after $18 \mathrm{hr}$ had full ovulations.

Table 1. Effect of LH on the number of rats ovulating after Caesarean Section

\begin{tabular}{l|l|c}
\hline \multicolumn{1}{c|}{ Treatment } & LH* & $\begin{array}{c}\text { No. of females } \\
\text { ovulating after 24 hr/ } \\
\text { total no. of females }\end{array}$ \\
\hline No CS & Intraperitoneal & $3 / 16^{*}$ \\
No CS & Intravenous & $27 / 35$ \\
CS on Day 22 at 09.00 hours & No LH & $4 / 20^{\mathrm{a}}$ \\
CS on Day 22 at 09.00 hours & Intraperitoneal & $14 / 17^{\mathrm{b}}$ \\
\hline
\end{tabular}

For a versus $b, P<0.01$.

* $40 \mathrm{mg}$ NIH-LH-S17.

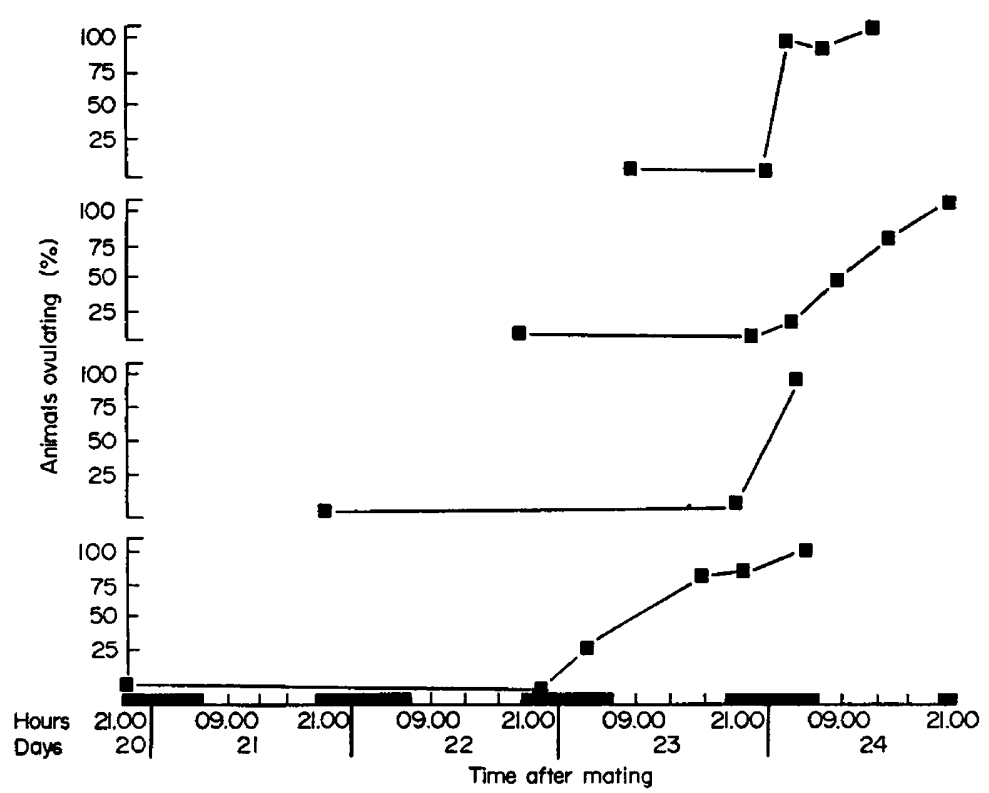

TeXT-FIG. 1. The time interval to ovulation after Caesarean Section of rats on Day 20, 21 or 22 at 21.00 hours and on Day 23 at 09.00 hours. The black bars represent the dark period of each $24 \mathrm{hr}$.

The exogenous $\mathrm{LH}$ was capable of inducing ovulation in pregnant females only if the mode of administration was intravenous. Intraperitoneal injection caused ovulation within $24 \mathrm{hr}$ in $19 \%$ of control females (no CS) and $82 \%$ of CS females $(P<0.001)$ (Table 1$)$.

Ovulation data from groups of females delivered by CS at 09.00 hours on Day 20, 21 or 22 are compared with the results of CS on Day 23 in Text-fig. 1.

It can be seen that all the females delivered by CS except the Day-20 group 
began to ovulate at approximately the same time, the early morning of Day 24, but the time taken to reach $100 \%$ ovulation varied. All the females delivered by CS on Day 20 had ovulated by Day 23, a full day earlier than when CS was performed on later days $(P<0.005)$. The slope of the lines for the Day-20 and Day-22 groups are alike, as are those of Day-21 and Day-23 animals. Of ten females which were subjected to CS at 21.00 hours on Day 19, seven had ovulated by 09.00 hours on Day 22, a full day earlier than the females delivered by CS on Day $20(P<0.01)$.

None of the ten females whose uterine horns had been ligated on Day 22 had ovulated by the afternoon of Day 24, but three out of eighteen had done so by Day 25, and two out of ten by the afternoon of Day 26. Similar groups of females with uterine ligatures were delivered by CS on Day 24 and killed on Day 25 or Day 26. The percentage of animals ovulating was not increased on either day.

\section{DISCUSSION}

All females delivered by Caesarean section on Day 23 of gestation at 09.00 hours ovulated after 24.00 hours (15 hr later) and before 03.00 hours (18 hr later), thus indicating that removal of the conceptuses from pregnant rats early on the usual day of parturition results in ovulation after an interval similar to, but slightly shorter than, that which would have occurred after normal parturition.

Since $15 \%$ of the pregnant females in our colony litter on Day 22 , the ovulation results from females delivered by CS at 09.00 hours on Day 22 should fit one of two hypotheses: (1) only those females which would normally litter on Day $22(15 \%)$ should ovulate during the first night after CS, or (2) all females should ovulate during the first night after CS. None of the ten females had ovulated by 10.00 hours of Day 22 (13 hr after CS). Only 20\% had ovulated by 04.00 hours on Day 23 or by noon on Day 23, indicating that the first hypothesis is probably correct; only those females which would normally have given birth on Day 22 will ovulate during the first night after CS on Day 22. Eleven of fifteen animals ovulated during the second night after CS (06.00 hours, Day 24). Hysterectomy did reduce the percentage of animals ovulating, but the reduction was not significantly different from that of the CS animals.

Data from females delivered by Caesarean Section early on Day 22 indicate that only those females which would usually deliver on Day 22 will ovulate during the first night after CS on Day 22. The significant increase in ovulation after exogenous $\mathrm{LH}$ indicates that the $80 \%$ of females delivered by CS on Day 22 which do not ovulate during the first night have failed to release LH during the critical period on the day of CS.

If CS was performed as early as Day 21 of gestation, the resulting ovulation occurred during the morning of Day 24. When CS was performed earlier than Day 21, it caused females to ovulate earlier than Day 24; if CS was performed on Day 20, females ovulated on Day 23; if performed on Day 19, females ovulated on Day 22. This suggests that luteal changes are usually 
completed by Day 21 and that from Day 21 until parturition, preovulatory conditions are being established. This would coincide with the findings of Wiest (1970) that serum, uterine, and ovarian progesterone levels have decreased by this time. In addition, Day 21 is approximately the time that Linkie \& Niswender (1972) first noted slight but significant elevations in the serum LH of pregnant female rats.

Females in which parturition was prevented by uterine ligation did not ovulate in significant numbers, and did not do so after GS on Day 24.

\section{AGKNOWLEDGMENTS}

This research was aided in part by grant MH 19716 from the National Institute of Mental Health. The NIH-LH-S17 was obtained through the courtesy of NIAMD. The rat colony is an outbred heterozygotic strain of Wistar-derived rats maintained by M.X.Z. since 1949.

\section{REFERENCES}

EveretT, J. W. (1964) Central neural control of reproductive functions of the adenohypophysis. Physiol. Rev. 44, 373.

Hoffmann, J. C. \& Schwartz, N. B. (1965) Timing of postpartum ovulation in the rat. Endocrinology, 76,620 .

Johnson, N. P. (1972) Postpartum ovulation in the rat. Doctoral dissertation, Purdue University, Lafayette Indiana.

LiNkie, D. M. \& Niswender, G. D. (1972) Serum levels of prolactin, luteinizing hormone and follicle stimulating hormone during pregnancy in the rat. Endocrinology, 90, 632.

WIEst, W. G. (1970) Progesterone and 20 $\alpha$-hydroxypregn-4-en-3-one in plasma, ovaries and uteri during pregnancy in the rat. Endocrinology, 87, 43.

Zarrow, M. X., Galdwell, A. L., Hafez, E. S. E. \& Pincus, G. (1958) Superovulation in the immature rat as a possible assay for LH and HCG. Endocrinology, 63, 748. 